\title{
Resolución alternativa de conflictos. Derechos del consumidor en los conflictos derivados del comercio electrónico transfronterizo
}

\author{
Alternative dispute resolution. \\ Consumer rights in disputes arising from cross-border e-commerce
}

\section{Angélica María Reyes Sánchez}

Abogada por la Universidad Santo Tomás Bucaramanga (Col.); magister en Hermenéutica Juridica y Derecho por la Universidad Industrial de Santander (Col.); estudios de Maestría en Derecho con énfasis en Derecho Empresarial y Contractual; grupo de investigación en Ciencia Politica y Derecho, Facultad de Derecho, Universidad Pontificia Bolivariana, Bucaramanga (Col.). Correo electrónico: angelica.reyes@upb.edu.co

\section{Luisa Fernanda García Salazar}

Abogada por la Universidad Santo Tomás Bucaramanga (Col.); magister en Derecho de la Empresa por la Universidad de Navarra, España; diplomada en Conciliación por la Universidad del Rosario y la Universidad Santo Tomás (Col.), curso de Negociación para Profesionales Universidad de Harvard, EE. UU.; docente Facultad de Derecho Universidad Santo Tomás Bucaramanga (Col.).

Correo electrónico: luisagarciasalazar@gmail.com

\begin{abstract}
Resumen
El comercio electrónico, como aquella posibilidad ofrecida por la globalización para el intercambio de bienes y prestación de servicios a partir del uso de medios electrónicos, ha permitido superar las fronteras establecidas por la soberanía de los Estados, sin embargo, la regulación que se hace de este siempre resulta siendo territorial, derivando conflictos para las partes de la relación, máxime cuando se encuentran ubicadas en espacios territoriales diferentes, perjudicando los intereses de la parte débil de la relación: el consumidor. A continuación, los avances de un proyecto de investigación que busca "analizar los fundamentos normativos en los países miembros del Mercosur y la CAN que permiten la aceptación de la regulación marco de la mediación en línea, como mecanismo de resolución de conflictos derivados del comercio electrónico transfronterizo" (García, Reyes \& Toro, 2014, p. 10).
\end{abstract}

Palabras clave: Comercio electrónico, consumidor, resolución de conflictos.

\begin{abstract}
The globalization offered the possibility for exchange of goods and services through the use of electronic media, has overcome the boundaries set by the sovereignty of States, perhaps, the regulation is always being territorial. The territorial regulation generates conflicts for the parties in their relationship, especially when they are located in different territorial spaces, damaging the interests of the weaker party in the relationship: the consumer. Then the progress of a research project that seeks to "analyze the normative foundations in member countries of Mercosur and CAN allowing the acceptance of the framework regulating online mediation as a mechanism for resolving disputes arising from electronic commerce border" (Garcia, Reyes $\&$ Toro, 2014, 10).
\end{abstract}

Keywords: Online mediation, e-commerce, consumer, conflict resolution.

\begin{abstract}
Résumé
Le commerce électronique, comme la possibilité offerte par la mondialisation pour l'échange de biens et services de l'utilisation des médias électroniques, a surmonté les limites fixées par la souveraineté des États, cependant, le règlement est pris ce toujours être territoriale, découlant des conflits pour les parties de la relation, surtout quand ils sont situés dans des zones territoriales différentes, porter atteinte aux intérêts de la partie la plus faible de la relation: le consommateur. Ensuite, l'état d'avancement d'un projet de recherche qui vise à «analyser les fondements normatifs dans les pays membres du Mercosur et peut permettre l'acceptation du cadre du règlement de médiation en ligne comme un mécanisme de règlement des différends découlant de e-commerce frontière «(Garcia, Reyes \& Toro, 2014, p. 10).
\end{abstract}

Mots-clés: E-commerce, la consommation, la résolution des conflits.

Recibido: 28 de junio de 2015; Aprobado: 10 de octubre de 2015 



\section{Resolución alternativa de conflictos.}

\section{Derechos del consumidor en los conflictos derivados del comercio electrónico} transfronterizo*

Angélica María Reyes Sánchez

Luisa Fernanda García Salazar

\section{INTRODUCCIÓN}

Las oportunidades que ofrece la globalización al ser humano para procurar la satisfacción de sus necesidades, ha horadado las fronteras territoriales que de antaño han parcializado el espacio de acción, obligando a algunas regiones a sentirse en evolución, cuando todos, como miembros de una comunidad conectada por las tecnologías de la información, constituyen piezas claves en la transformación social, el desarrollo y la convivencia.

En el marco de la globalización, las tecnologías de la información y la comunicación constituyen una herramienta que desdibuja las fronteras tradicionalmente establecidas y ubica a todos los ciudadanos en el mismo plano, que en términos de intercambio de bienes y servicios se conoce como mercado. Sin embargo, la ubicación en este plano trae consigo el juego de poderes, demarcando privilegios a quienes cuentan con los recursos y medios en perjuicio del sometimiento del más débil: el consumidor ${ }^{1}$.

* $\quad$ El texto es producto del proyecto de investigación: "Fundamentos normativos de la mediación en línea de los conflictos derivados del comercio electrónico transfronterizo: Estudio del caso Mercosur y Can", presentado en conjunto UPB - USTA, aprobado en convocatoria interna de investigación 2014 y VIII, respectivamente.

1 El ordenamiento jurídico colombiano ha reconocido como consumidor a toda persona natural o jurídica que, como destinatario final, adquiera, disfrute o utilice un determinado producto, cualquiera que sea su naturaleza para la satisfacción de una necesidad propia, privada, familiar o doméstica y empresarial cuando no esté ligada intrínsecamente a su actividad económica. Se entenderá incluido en el concepto de consumidor el de usuario (República de Colombia, 2011, art. 49). 
A los avances tecnológicos se suma el progreso que ha representado la globalización y la intervención de todos en las relaciones dinámicas que se desarrollan en dicho marco, tales son las relaciones de consumo que se derivan del comercio electrónico, traspasando las fronteras territoriales y permitiendo el intercambio de bienes y servicios con el uso de herramientas tecnológicas, entre ellas la internet.

Frente a esta dinámica del mercado, los ordenamientos jurídicos del mundo intentan, de manera permanente, contrarrestar las consecuencias de las relaciones comerciales internacionales, de las cuales interesan, a los fines de la presente disertación, aquellas referidas al comercio electrónico.

Es en la relación de consumo, que surge en el marco del comercio electrónico, donde se centra el interés investigativo, pues de la misma, atendiendo a sus características, se derivan múltiples conflictos que, en la mayoría de casos, se traducen en violación a los derechos del consumidor, quien prima facie es la parte débil de la relación.

Las características que interesan al comercio electrónico referido, ubican la investigación en el denominado comercio electrónico transfronterizo, en virtud del cual el proveedor, productor o distribuidor se encuentra ubicado fuera del territorio nacional del consumidor.

En Colombia, el marco jurídico para las relaciones de consumo se encuentra integrado, entre otras, por la Ley 1480 de $2011^{2}$ por medio de la cual se expide el estatuto del consumidor y se incluye la regulación de las relaciones derivadas del comercio electrónico, sin embargo, excluye de la misma a los proveedores, productores o distribuidores ubicados fuera del territorio nacional, por lo que se parte de la premisa de incluir, como medios de protección, la regulación que se ha gestado en el marco internacional, especialmente por las comunidades económicas en las que participa Colombia.

Entre las comunidades económicas referidas, llama la atención lo establecido por el Mercado Común del Sur - Mercosur³ , la Comunidad Andina de Naciones

2 Dentro de los principios generales la ley se encuentra proteger, promover y garantizar la efectividad y el libre ejercicio de los derechos de los consumidores, así como amparar el respeto a su dignidad y a sus intereses económicos (Congreso de la República, 2011, art. 5). Esta Ley ha sido objeto de críticas favorables y no tan favorables en el marco de su regulación, así Remolina (2012, pp. 2-199) afirma que la norma "en buena parte se pone a tono con las realidades económicas y las necesidades de los consumidores".

3 El Mercado Común del Sur - Mercosur está integrado por la República Argentina, la República Federativa de Brasil, la República del Paraguay, la República Oriental del Uruguay, la República Bolivariana de Venezuela y el Estado Plurinacional de Bolivia.

Los Estados Partes que conforman el Mercosur comparten una comunión de valores que encuentra expresión en sus sociedades democráticas, pluralistas, defensoras de las libertades fundamentales, de los derechos humanos, de la protección del medio ambiente y del desarrollo sustentable, así como su compromiso con la consolidación de la democracia, la seguridad jurídica, el combate a la pobreza y el desarrollo económico y social con equidad. Colombia es Estado asociado, teniendo como derecho la participación en las reuniones y la suscripción de acuerdo, de conformidad con las disposiciones establecidas para estos efectos (Mercosur, s.f. Sitio Web oficial). 
- $\mathrm{CAN}^{4}$ y las propuestas que la Comisión de la Naciones Unidas para el Derecho Mercantil Internacional - CNUDMI . Por lo anterior, los avances en la protección de los derechos del consumidor en el marco del comercio electrónico que estas comunidades proponen, son referente necesario a la hora de intervenir el mercado en procura de un adecuado desarrollo de la relación de consumo que se hace a través de medios tecnológicos.

\section{CONSUMIDOR - COMERCIO ELECTRÓNICO: BLOQUES ECONÓMICOS E INTEGRACIÓN}

La seguridad jurídica que puede ofrecer un ordenamiento a los diferentes actores del mercado constituye uno de los principales deberes del Estado. Así lo reconoce la Constitución Política de Colombia al imponer como fines del Estado social de derecho, entre otros: "promover la prosperidad general y garantizar la efectividad de los principios, derechos y deberes consagrados en la Constitución (...) asegurar la convivencia pacífica y la vigencia de un orden justo" (Asamblea Nacional Constituyente, 1991, art. 2), y el deber que impone a las autoridades de la República al advertir que "están instituidas para proteger a todas las personas residentes en Colombia, en su vida, honra, bienes, creencias y demás derechos y libertades, y para asegurar el cumplimiento de los deberes sociales del Estado y de los particulares" (Subrayado fuera de texto) (Asamblea Nacional Constituyente, 1991, art. 2).

Lo anterior denota la importancia de una regulación que garantice los derechos de los consumidores como uno de los principales agentes del mercado, base de la estructura económica de la sociedad y último eslabón de la cadena de distribución como destinatario final. Es así como por mandato constitucional:

la ley regulará el control de calidad de bienes y servicios ofrecidos y prestados a la comunidad, así como la información que debe suministrarse al público en su comercialización.

Serán responsables, de acuerdo con la ley, quienes en la producción y en la comercialización de bienes y servicios, atenten contra la salud, la seguridad y el adecuado aprovisionamiento a consumidores y usuarios (Asamblea Nacional Constituyente, 1991, art. 78).

Esta disposición constitucional se ha traducido en diversas regulaciones legales que han pretendido garantizar a los consumidores el reconocimiento y respeto de

4 La Comunidad Andina de Naciones es una organización que tiene como objetivo alcanzar un desarrollo integral más equilibrado y autónomo, mediante la integración andina, suramericana y latinoamericana. Conformada por Bolivia, Colombia, Ecuador y Perú (CAN, s.f. Sitio Web oficial).

5 "Órgano jurídico de composición universal, dedicado a la reforma de la legislación mercantil a nivel mundial durante más de 40 años. La función de la CNUDMI consiste en modernizar y armonizar las reglas del comercio internacional" (CNUDMI, s.f. Sitio Web oficial). 
sus derechos, se destaca la Ley 1480 de 2011 como una de las aproximaciones más cercanas a los parámetros internacionales en tema de protección al consumidor, sin embargo, en el marco del comercio electrónico, específicamente del realizado en el ámbito transfronterizo, el ordenamiento jurídico no garantiza a los colombianos un marco mínimo de protección a sus derechos, pues impone obligaciones solo al proveedor o expendedor ubicado en el ámbito nacional.

Lo anterior podría generar inconvenientes en un mundo globalizado donde la adquisición de bienes y servicios se realiza, cada vez con mayor frecuencia, a través de medios electrónicos. Sin embargo, lo anterior no justifica que el consumidor se quede sin respuestas frente a posibles conflictos que puedan surgir con sus proveedores, específicamente en torno a sus derechos y mecanismos de protección a los mismos, por ello se propone que la regulación internacional de las comunidades económicas en las que participa Colombia, sea el referente para su protección.

Por ello resulta pertinente describir el estado de avance de Mercosur, CAN y CNUDMI en torno a la protección del consumidor en el comercio electrónico, pues los propósitos de protección son comunes a todos y las barreras desdibujadas por el uso de tecnologías de la información y la comunicación exigen una respuesta que rompa igualmente dichas fronteras, con las precisiones constitucionales que cada país pueda realizar en procura de la integración económica que los países latinoamericanos promueven.

Por lo anterior, se han establecido bloques económicos que buscan la eliminación de fronteras y obstáculos que puedan retrasar la dinámica del mercado. Entre ellos, el Mercosur, de acuerdo con el Tratado de Asunción, como bloque implica:

1. La libre circulación de bienes, servicios y factores productivos entre los países, a través, entre otros, de la eliminación de los derechos aduaneros y restricciones no arancelarias a la circulación de mercaderías y de cualquier otra medida equivalente;

2. El establecimiento de un arancel externo común y la adopción de una política comercial común con relación a terceros Estados o agrupaciones de Estados y la coordinación de posiciones en foros económicos, comerciales, regionales e internacionales;

3. La coordinación de políticas macroeconómicas y sectoriales entre los Estados Partes: de comercio exterior, agrícola, industrial, fiscal, monetarias, cambiarias y de capitales, de servicios, aduanera, de transportes y comunicaciones y otras que se acuerden, a fin de asegurar condiciones adecuadas de competencia entre los Estados Partes;

4. El compromiso de los Estados Partes de armonizar sus legislaciones en las áreas pertinentes, para lograr el fortalecimiento del proceso de integración (Mercosur, 1991, art. 1). 
De los propósitos enunciados, se destaca el compromiso de armonizar las legislaciones en las áreas pertinentes, reto que impone a cada Estado el trato jurídico igualitario en los temas que resultan comunes al bloque, entre ellos el comercio electrónico.

Frente al comercio electrónico, Mercosur NO ha establecido una regulación modelo que otorgue un marco jurídico confiable al consumidor, lo que se deduce de un diagnóstico realizado (2011) al marco jurídico vigente de sus países miembros, seguido de la alianza con la Comunidad Europea para adelantar diagnóstico y análisis de la situación de la economía digital en la región del Mercosur y América Latina que:

Culminó con la entrega de un Plan Director, su Plan Operacional y las acciones específicas propuestas para su puesta en Marcha en la región, a ser implementado en los próximos 3 a 5 años.

El Plan Director, desde una perspectiva estratégica, busca orientar, definir prioridades y estimular las inversiones del sector para potenciar las condiciones económicas y sociales de los países del Mercosur a través del crecimiento del Ecosistema de la Economía Digital. Propone el desarrollo de las Tecnologías de la Información y Comunicación (TIC) apoyado en políticas públicas adecuadas, y propuestas de carácter multisectorial, con la inclusión de las PyME como motor fundamental para el aumento del intercambio transfronterizo fluido entre los países de la región (Mercosur, s.f, p. 46).

En esta medida, el bloque económico reconoce que las tecnologías de la información y la comunicación son un elemento que apalanca la evolución del comercio y los negocios electrónicos, haciendo posible el funcionamiento de la economía global, sin embargo, impone una reingeniería en las formas de relación de los agentes que intervienen en el mercado y en consecuencia de los insumos de regulación que se han establecido para su adecuado desarrollo, entre ellas el uso de tecnologías de información y comunicación - TIC, pues no cabe duda que contribuye al desarrollo de la gestión empresarial contemporánea (Remolina, 2006, pp. 323-370).

Por lo anterior, el estudio ha tomado en cuenta un diagnóstico de todas las condiciones necesarias para la implementación del modelo, comenzando por las oportunidades de bienes y servicios, seguido de los proveedores y consumidores, los agentes intermediarios y colaboradores del sistema, entre otros, pues el comercio electrónico y los negocios por internet, para ser eficiente y pujante.

Constituye una construcción que requerirá del esfuerzo colaborativo y constante de quienes se constituyan como líderes y coordinadores pero asimismo, de todos los actores involucrados en el Ecosistema, teniendo en cuenta las profundas transformaciones originadas en el desarrollo y difusión de las Tecnologías de la Información y las Comunicaciones en la sociedad.

Por ello, el camino de nuestras sociedades hacia los nuevos paradigmas comerciales y productivos más eficientes, integrados, transparentes, estandarizados y armónicos, deberá ser transitado por la sociedad en su conjunto, como un proceso progresivo de cara al futuro (Mercosur, s.f., p. 51). 
En este sentido, el compromiso de integración puede recoger los propósitos del plan directivo que apunta al desarrollo del comercio electrónico entre los países miembros $\mathrm{y}$ asociados del Mercosur y, en este marco, los derechos del consumidor deben ser tenidos como prioridad en la agenda de regulación de este bloque económico.

Dentro de las organizaciones económicas se encuentra también la CAN, ha reconocido el estado de avance y evolución del comercio electrónico y la categorización que el ranking elaborado por The Economist Intelligence y el Ebussiness Forum, en cuatro grupos, dentro del cual se encuentran los seguidores (followers) del $e$-Bussines. Este grupo es mayoritario y los países que lo integran han comenzado a crear un ambiente propicio para el e-Business, sin embargo, existen aún avances por desarrollar. Dentro de este grupo se encuentran varios países latinoamericanos, entre ellos Colombia (CAN, 2002, p. 13).

En el marco del objetivo de la CAN, establecida para "promover el desarrollo armónico y equilibrado de sus países Miembros, mediante la integración y la cooperación económica y social; así como, disminuir la vulnerabilidad externa y mejorar la posición de los países Miembros en el contexto económico internacional" (CAN, 2002, p. 14), el comercio electrónico ha sido de múltiples debates y reuniones $\mathrm{y}$ en virtud del mismo se han establecido recomendaciones como:

- Ejecutar un plan integral para superar las dificultades y obstáculos que impiden el desarrollo del comercio electrónico.

- Exhortar a los países de la Comunidad Andina a que aproximen su legislación sobre la materia, para su posterior armonización, contribuyendo así al establecimiento del Mercado Común.

- Evaluar todos y cada uno de los cuerpos jurídicos de cada país para evitar contradicciones o posteriores acciones en contra de las leyes Marco que se implementen.

- Establecer los mecanismos e instrumentos jurídicos que brinden seguridad a las transacciones comerciales que se realizan por el medio digital.

- Lograr la consolidación del principio de equivalencia funcional del documento electrónico y firma electrónica en las leyes, para que puedan competir en igualdad de condiciones con los documentos tradicionalmente aceptados (CAN, 2002, p. 14).

A partir de estas recomendaciones, la CAN realiza diagnóstico de la legislación de sus países miembros a fin de establecer directrices que posibiliten la armonización a través de una directriz comunitaria. Los temas de regulación analizados giran en torno a mensajes de datos, firma electrónica, certificados digitales, entidades/ autoridades de certificación y registro, dejando para un segundo reporte el análisis de los demás temas, dentro de los cuales es imperativo que se involucre el tema del consumidor, sus derechos y sus posibilidades de protección, especialmente frente al proveedor ubicado fuera del territorio nacional. 
El análisis propiciado por la $\mathrm{CAN}$ reconoce los avances que en tema de comercio electrónico han desarrollado la Comunidad Económica Europea y las Naciones Unidas, a través de la CNUDMI, por lo que resulta pertinente revisar lo previsto por esta comisión.

La CNUDMI cuenta con una ley modelo para el comercio electrónico que tiene como objetivo:

posibilitar y facilitar el comercio por medios electrónicos ofreciendo a los legisladores un conjunto de reglas internacionalmente aceptables encaminadas a suprimir los obstáculos jurídicos y a dar una mayor previsibilidad al comercio electrónico. En particular, la Ley Modelo tiene la finalidad de superar los obstáculos que plantean las disposiciones legislativas y que no pueden modificarse mediante contrato equiparando el trato dado a la información sobre papel al trato dado a la información electrónica. Esa igualdad de tratamiento es esencial para hacer posibles las comunicaciones sin soporte de papel y para fomentar así la eficacia en el comercio internacional (CNUDMI, 1996).

Aunado a lo anterior, la Ley Modelo va acompañada de una Guía para la incorporación al derecho interno que ofrece antecedentes y explicaciones para ayudar a los Estados a preparar las disposiciones legislativas necesarias y para orientar a otros usuarios del texto (CNUDMI, 1996).

En el marco de esta ley modelo, las naciones unidas reconocen la necesidad de regular el tema, porque:

El régimen aplicable en ciertos países a la comunicación y archivo de información era inadecuado o se había quedado anticuado, al no haberse previsto en ese régimen las modalidades propias del comercio electrónico. En algunos casos, la legislación vigente impone o supone restricciones al empleo de los modernos medios de comunicación, por ejemplo, por haberse prescrito el empleo de documentos "originales", "manuscritos" o "firmados". Si bien unos cuantos países han adoptado reglas especiales para regular determinados aspectos del comercio electrónico, se hace sentir en todas partes la ausencia de un régimen general del comercio electrónico (CNUDMI, 1996, Guía).

Lo anterior evidencia el compromiso de la comunidad internacional frente a las nuevas modalidades de comercio, modalidades que han superado las barreras impuestas por las fronteras y exigen que los países dispongan de los medios para la armonización de una regulación para el comercio electrónico.

Sin embargo, los retos son importantes, toda vez que las regulaciones que se han podido gestar hasta el momento, siguen dejando al consumidor en un marco cerrado que nada dice frente a la protección de sus derechos, específicamente frente al poder del proveedor ubicado fuera de su territorio de origen, esto es los derechos del consumidor en el comercio electrónico transfronterizo. 
Lo anterior teniendo en cuenta el marco de la economía que caracteriza a los países latinoamericanos y las barreras que se están superando en los diferentes temas que aquejan a cada una de las naciones. Es la oportunidad de aunar esfuerzos por el desarrollo y crecimiento social y económico de nuestros países.

Los propósitos de cada país, reunidos en las comunidades o bloques económicos son una alternativa al reconocimiento y protección del mercado, a través de la protección del consumidor. Ya existen ejemplos exitosos de regulaciones comunitarias que promueven la protección del consumidor en el marco del comercio electrónico.

Estos modelos se encuentran representados en la Comunidad Europea - UE y la Organización para la Cooperación y Desarrollo Económicos OCDE. La primera ha establecido diez principios básicos para la protección de los consumidores en la Unión Europea (2005). La Comisión Europea ha diseñado un instructivo bastante asequible para el consumidor a partir de "los diez principios básicos en los que se basa la legislación comunitaria relativa a la protección de los consumidores, los cuales son de rigurosa aplicación en todos y cada uno de los Estados miembros de la UE". Compre lo que quiera, donde quiera; si no funciona, ¡devuélvalo!, normas estrictas de seguridad alimentaria y relativas a otros bienes de consumo; ¿sabemos lo que comemos?; los consumidores merecen todo el respeto, también en los contratos de venta; cambiar de opinión, también está permitido, busque y compare... el mejor precio; practiquemos el juego limpio con los consumidores; vacaciones y protección de derechos e indemnizaciones efectivas en caso de litigios transfronterizos.

Por otra parte, la OCDE (2003) ha adoptado como recomendación las directrices para la Protección de los Consumidores de Prácticas Comerciales Transfronterizas Fraudulentas y Engañosas. Estas disposiciones fueron elaboradas por el Comité de Políticas del Consumidor.

Las directrices de la OCDE contemplan los eventos que constituyen prácticas fraudulentas y engañosas que perjudican los intereses del consumidor y establece mecanismos de protección y resarcimiento para este, siendo un ejemplo muy detallado de los beneficios que el consumidor tiene frente a proveedores que intervienen en el mercado generando daños a los demás agentes del mismo.

Estos modelos de regulación resultan avanzados frente a los establecidos por los países y comunidades de Latinoamérica y pueden representar un parámetro que posibilite la protección del consumidor. Una protección de la comunidad latinoamericana para sus miembros, un ejercicio de soberanía que supere las fronteras territoriales establecidas y que en procura de un interés común se sobreponga a las particularidades económicas y culturales que la caracteriza, un consenso vinculante para todos en procura del desarrollo económico y social de la región que ofrezca garantías de inversión y participación en el mercado. 


\section{PROTECCIÓN AL CONSUMIDOR EN EL COMERCIO ELECTRÓNICO TRANSFRONTERIZO}

Los retos de la globalización y el desarrollo tecnológico han marcado transformaciones significativas a las relaciones humanas, especialmente aquellas dirigidas a la satisfacción de las necesidades básicas de subsistencia. Dentro de estas transformaciones se destacan los avances en torno al comercio electrónico, pues constituye, además, una dinámica del mercado que ignora las fronteras territoriales impuestas desde épocas remotas.

De esta manera, dos personas ubicadas en lugares distantes entre sí pueden establecer un acuerdo para el suministro de bienes o la prestación de servicios, a través del uso de medios tecnológicos, surgiendo obligaciones para uno y en su lugar derechos para el otro, sin embargo, los desarrollos jurídicos, específicamente para la protección del consumidor, responden de manera tardía a los avances del mercado globalizado, dejando circunstancias sin regulación clara aplicable y en consecuencia gestando posiciones de desprotección.

En este marco, los países latinoamericanos aúnan esfuerzos para superar las circunstancias económicas y culturales que caracterizan la región, se han propuesto establecer alianzas, comunidades y bloques que procuran la cooperación en persecución de estos fines, siendo los más representativos Mercosur, CAN y CNUDMI.

Cada uno de los bloques descritos reconoce la importancia del comercio electrónico para el desarrollo de los pueblos y ha dispuesto los medios para reconocer el estado actual del mercado y proponer regulaciones comunes que sean armonizadas por los ordenamientos internos, sin embargo, no todos los países miembros o asociados se encuentran preparados desde sus postulados constitucionales y legales, por lo que es necesaria una consideración en este sentido, atendiendo las recomendaciones que el diagnóstico ha arrojado.

Existen en el mundo diversos grupos económicos y el éxito de los mismos se encuentra sujeto a la protección de derecho y la existencia de mecanismos coactivos significativos que garanticen dicha protección. Un ejemplo de ello son la UE y la OCDE, modelos que reconocen en el consumidor el protagonismo del mercado, imponiendo a los demás agentes obligaciones que lo vinculen al reconocimiento y respeto de dichos derechos.

Estos referentes y experiencias deben marcar la diferencia para la propuesta latinoamericana. Una propuesta que reconozca su identidad, sus circunstancias, los intervinientes y las problemáticas en aras de responder, como uno solo, a los retos que la globalización y las tecnologías de la información y la comunicación imponen a sus formas negociales y con ello al desarrollo económico y social de la región.

Todo lo anterior evidencia la necesidad de evaluar nuestras economías y ordenamientos jurídicos, diagnosticar las debilidades y fortalezas, identificar el estado de preparación de cada uno de nuestros países y las contribuciones que cada 
uno puede ofrecer a la integración latinoamericana, en procura de los derechos del consumidor, pues la regulación desarrollada hasta el momento contempla aspectos técnicos ajenos al consumidor.

En Colombia se han gestado propuestas que cada día resultan más cercanas a los propósitos comunitarios, sin embargo, en torno a la protección del consumidor en el comercio electrónico transfronterizo ha dejado un espacio que debe ser armonizado con las regulaciones existentes en los bloques o comunidades en las que participa, sea como miembro o como asociado.

Lo anterior es solo una medida provisional, pues la verdadera solución impone la integración latinoamericana en procura del desarrollo económico y social de la región a través de modelos económicos y jurídicos que armonicen los diversos ordenamientos, sin embargo, esto no será viable sin el reconocimiento previo de un diagnóstico del estado económico y jurídico de nuestros países, de nuestra región.

\section{CONCLUSIONES}

El contexto que soporta la investigación, parte de un marco inicial propio de los derechos del consumidor y la relación de consumo, integrada, por una parte, por el proveedor o distribuidor de bienes o servicios y, por la otra, al destinatario final de esos bienes o servicios para la satisfacción de sus necesidades domésticas, familiares e incluso empresariales, siempre que no estén vinculadas con su objeto social, así lo define la el Estatuto del Consumidor.

Con todas las observaciones jurídicas que puedan hacerse, el Estatuto del Consumidor ha intentado desarrollar los fundamentos constitucionales que enmarcan la relación de consumo, representando un avance, en la medida de lo posible, en la protección a los derechos del consumidor. Lo anterior reforzado por la inclusión del comercio electrónico como una alternativa para el intercambio de bienes o servicios mediante el uso de medios electrónicos, como una posibilidad para la consolidación de la relación de consumo.

En el comercio electrónico, las partes de la relación de consumo se mantienen con las características que se han mencionado, sin embargo se encuentra una característica adicional: las partes se encuentran ubicadas en lugares diferentes, incluso por fuera del mismo territorio nacional, por lo que el consumidor no conocerá un establecimiento de comercio en los términos tradicionalmente conocidos. A esta posibilidad de que el proveedor o distribuidor se encuentre ubicado fuera del territorio nacional del consumidor se le ha denominado comercio electrónico transfronterizo.

De esta manera, la problemática se va centrando en el comercio electrónico transfronterizo, en la medida en que los derechos, deberes y obligaciones consagrados por el Estatuto del consumidor son aplicables solo a las relaciones establecidas con proveedores ubicados en el territorio nacional del consumidor, dejando sin una protección formal al consumidor cuyo proveedor se encuentra ubicado fuera del territorio nacional. 
En este marco se formula el problema de investigación toda vez que actualmente la resolución de los conflictos derivados del comercio electrónico transfronterizo se da a partir de lo establecido en las condiciones contractuales y el conflicto se agrava por las características de adhesión del contrato que se suscribe o, en la peor de las circunstancias, la falta de diligencia del consumidor de informarse de las condiciones contractuales, acuerdo que siempre debe ejecutarse bajo los postulados de la buena fe y la autonomía de la voluntad.

Frente a estas circunstancias existen mecanismos alternativos para la resolución de conflictos que han sido desarrollados, como es el caso del arbitraje, sin embargo, no resulta un mecanismo adecuado para la resolución de conflictos derivados de la relación de consumo por los costos y tiempos que implica el arbitramento y la relación costo-beneficio con el bien o servicio adquirido y el reclamo que el consumidor presenta. Por lo anterior, se confían en la mediación en línea como el mecanismo jurídico expedito para la resolución de este tipo de conflictos.

Pese a lo anterior, la medición en línea se ha ido estableciendo mediante acciones voluntarias del empresario que incluyen en su portal web el espacio para la mediación, tendientes a obtener buenas calificaciones del servicio o por manuales de buenas prácticas. Mientras en Europa se han establecido disposiciones que regulan la figura, en América Latina no se cuenta con avances significativos en este sentido, de allí que la investigación que se adelanta se ha concentrado en la CAN y Mercosur, con un respaldo en las disposiciones de ley modelo para la mediación en línea que está formulando CNUDMI, así como los propósitos de armonización e integración latinoamericana, se ha formulado un problema de investigación que busca responder ¿Cuáles son los fundamentos normativos en los países miembros de Mercosur y CAN que permiten la aceptación de la regulación marco de la mediación en línea como mecanismo de resolución de conflictos derivados del comercio electrónico transfronterizo?

En este sentido la investigación ha comenzado con el análisis de la relación de consumo y específicamente con el soft law que ha caracterizado la inclusión de la mediación en línea como mecanismo para la resolución de conflictos, propia de la dinámica empresarial que el mercado impone al empresario, sin embargo, por la falta de carácter vinculante de la medida, para el consumidor esta inclusión voluntaria representa falsas expectativas, inseguridad jurídica, desconfianza, generando afectaciones a la relación de consumo como base del mercado.

Por lo anterior, y en aras de asegurar el adecuado funcionamiento del comercio electrónico, Mercosur y CAN han establecido un conjunto de estudios de diagnóstico que reconocen en el comercio electrónico una alternativa esencial para el desarrollo y potencialización de la relación de consumo, figura que debe ser favorecida, sin embargo, en torno a los derechos del consumidor no se han establecido propósitos de armonización.

Un estudio inicial de las condiciones del ordenamiento jurídico colombiano permite observar la existencia de una constitución económica que consagra la importancia del mercado, la libertad de empresa, la iniciativa privada y la 
participación del consumidor en la relación de consumo, como la parte débil de ésta, al ser el destinatario final de la cadena de distribución, dentro de las disposiciones legales, en las que se encuentra una regulación técnica del comercio electrónico, encontrando sintonía con las disposiciones de la CAN y la Mercosur.

En este marco jurídico, Colombia cuenta con un catálogo de derechos del consumidor, establecidos en la Ley 1480 de 2012, que son aplicables también al comercio electrónico, siempre con la limitante de la ubicación del proveedor o distribuidor. En este conjunto de derechos, es importante resaltar el derecho de reclamación que se dificulta cuando la relación de consumo se ha realizado por medios electrónicos, atendiendo a la falta de regulación formal que obligue al empresario posibilitar los medios para el ejercicio de este derecho.

Con la ley modelo para la medicación en línea se puede suponer que, por los compromisos de armonización, cada Estado deberá adoptar las medidas para establecer la mediación en línea, señalando principios, deberes, obligaciones y derechos que permitan su aplicación como mecanismo alternativo de resolución de conflictos, incluyendo el carácter vinculante del acuerdo que logren empresario y consumidor para resolver su conflicto.

Así se presentan avances en torno al contexto jurídico y económico que caracterizan el comercio electrónico transfronterizo, los conflictos y posibilidades de resolución que pueden presentarse y los fundamentos normativos de los países miembros de Mercosur y CAN, resaltando avances en la Unión Europea y la OCDE, que sirven como modelos para seguir, siempre reconociendo las particularidades de la integración latinoamericana y los retos que la armonización implica.

Lo anterior con el propósito de describir la situación jurídica de los países miembros de CAN y Mercosur y explorar alternativas de complementación que permitan la armonización adecuada para la protección de los derechos del consumidor, teniendo en cuenta que, en Colombia, se han gestado propuestas que cada día resultan más cercanas a los propósitos comunitarios, sin embargo, en torno a la protección del consumidor en el comercio electrónico transfronterizo, ha dejado un espacio que debe ser armonizado con las regulaciones existentes en los bloques o comunidades en las que participa, sea como miembro o como asociado, a partir de esos propósitos de integración latinoamericana $\mathrm{y}$, en todo caso, en procura de la protección de los derechos del consumidor.

\section{REFERENCIAS}

Asamblea Nacional Constituyente. (1991). Constitución Política de Colombia. Bogotá D.C. CAN. (2002). Legislación sobre Comercio Electrónico en los países miembros de la comunidad Andina. Análisis comparativo, recomendaciones parasuarmonización. Con apoyo de Unión Internacional de Telecomunicaciones. Recuperado de http:// www.itu.int/ITU-D/cyb/publications/archive/Legislacion\%20Comercio\%20 Electronico\%20CAN1.pdf 
CAN. (s.f.). Recuperado de http://www.comunidadandina.org/Quienes.aspx

CNUDMI. (1996). Ley Modelo sobre Comercio Electrónico. Recuperado de http://www.uncitral.org/pdf/spanish/texts/electcom/05-89453_S_Ebook.pdf

CNUDMI. (s.f.). Recuperado de http://www.uncitral.org/uncitral/es/about_us.html

Comisión Europea. (2005). La protección de los consumidores en la Unión Europea.

CNUDMI. (1999). Ley 527 "Por medio de la cual se define y reglamenta el acceso y uso de los mensajes de datos, del comercio electrónico y de las firmas digitales, y se establecen las entidades de certificación y se dictan otras disposiciones". Bogotá, D.C.

CNUDMI. (2009). Ley 1340 "Por medio de la cual se dictan normas en materia de protección de la competencia". Bogotá, D.C.

CNUDMI. (2011). Ley 1480 "Por medio de la cual se expide el Estatuto del Consumidor y se dictan otras disposiciones". Bogotá, D.C.

Congreso de Colombia. (1959). Ley 155 "Por la cual se dictan algunas disposiciones sobre prácticas comerciales restrictivas”. Bogotá, D.C.

Congreso de Colombia. (2011). Ley 1480 "Por medio de la cual se expide el Estatuto del Consumidor".

Corte Constitucional, Colombia. (1992). Sentencia T - 425. Bogotá, D.C. M. P.: Ciro Angarita Pabón.

Corte Constitucional, Colombia. (1993). Sentencia C - 040. Bogotá, D.C. M. P.: Ciro Angarita Pabón.

Corte Constitucional, Colombia. (1994). Sentencia T - 291. Bogotá, D.C. M. P.: Eduardo Cifuentes Muñoz.

Corte Constitucional, Colombia. (1995). Sentencia C - 524. Bogotá, D.C. M. P.: Carlos Gaviria Díaz.

Corte Constitucional, Colombia. (1997). Sentencia T - 375. Bogotá, D.C. M. P.: Vladimiro Naranjo Mesa.

Corte Constitucional, Colombia. (1998). Sentencia C - 624. Bogotá, D.C. M. P.: Alejandro Martínez Caballero.

García, L. F., Reyes, A. M. y otro. (2013). Fundamentos normativos de la mediación en línea de los conflictos derivados del comercio electrónico transfronterizo: Estudio del caso Mercosur y Can (p. 27). Propuesta de Investigación. Convocatorias Internas de Investigación, Bucaramanga: Universidad Santo Tomás y Universidad Pontificia Bolivariana.

López, J. (s.f.). Constitución Económica: mercado y derecho de consumo. En ConTexto, 24-30.

Mercosur. (1991). Tratado para la constitución de un mercado común.

Mercosur. (2011). Consultoría para análisis de la logística, aspectos aduaneros e impositivos en Mercosur y América Latina relacionados con el comercio electrónico y negocios por internet transfronterizos. Recuperado de http://www. 
mercosurdigital.org/img/4.1MD-ComercioElectronico_NormativaRC02.1partel.pdf

Mercosur. (s.f.). Recuperado de http://www.mercosur.int/t_generic.jsp?contentid=38 $62 \&$ site $=1 \&$ channel $=$ secretaria

Mercosur. (s.f.). Proyecto Mercosur Digital. Ecosistemas del comercio electrónico $y$ negocios por internet transfronterizo. Recuperado de http://www. mercosurdigital.org/img/1MD-ComercioElectronico_EcosistemaRC02.2.pdf

Ministerio de Desarrollo Económico. (1992). Decreto 2153 "Por el cual se reestructura la Superintendencia de Industria y Comercio y se dictan otras disposiciones". Bogotá, D. C.

Naciones Unidas. (1996). UNCITRAL. Ley Modelo de Comercio Electrónico.

OCDE. (2003). Directrices para la protección de los consumidores de prácticas comerciales fraudulentas y engañosas. Recuperado de http://www.oecd.org/sti/ consumer/34012151.pdf

ONU. (2009). Estudio sobre las perspectivas de la armonización de la ciberlegislación en América Latina. New York y Ginebra. Conferencia de las Naciones Unidas sobre el Comercio y el Desarrollo. Recuperado el 4 de abril de 2014 de http:// unctad.org/es/docs/webdtlktcd20091_sp.pdf

Portafolio. (mayo, 2012). Comercio electrónico creció 42,8\% en América Latina en 2011. Bogotá, D.C. Recuperado el 23 de febrero de 2013 de http://www. portafolio.co/economia/comercio-electronico-crecio-428-america-latina-2011

Portafolio. (diciembre, 2013). El comercio electrónico creció 40\% en el 2013. Bogotá, D.C. Recuperado el 4 de abril de 2014 de http://www.portafolio.co/negocios/ comercio-electronico-el-2013

Remolina, N. (2006). Aspectos legales del comercio electrónico, la contratación y la empresa electrónica. Revista de Derecho Comunicaciones y Nuevas Tecnologías, 323-370. Bogotá: Universidad de los Andes. Recuperado de http://derechoytics. uniandes.edu.co/components/com_revista/archivos/derechoytics/ytics77.pdf

Remolina, N. (2012). La protección del consumidor en el contexto del comercio electrónico. Revista de Derecho Comunicaciones y Nuevas Tecnologías, 2-19. Bogotá: Universidad de los Andes. Recuperado de http://derechoytics.uniandes. edu.co/components/com_revista/archivos/derechoytics/ytics115.pdf

Unión Europea. (2005). La protección de los consumidores en la Unión Europea: Diez principios básicos. Recuperado de http://ec.europa.eu/consumers/cons info/10principles/es.pdf 